\title{
The NIHR Public Health Research Programme: responding to local authority research needs in the United Kingdom
}

\author{
Hannah Dorling ${ }^{1 *}$, Andrew Cook $^{2,3}$, Liz Ollerhead $^{1}$ and Matt Westmore
}

\begin{abstract}
The remit of the National Institute for Health Research Public Health Research (PHR) Programme is to evaluate public health interventions, providing new knowledge on the benefits, costs, acceptability and wider impacts of interventions, set outside of the National Health Service, intended to improve the health of the public and reduce inequalities. This paper illustrates how the PHR Programme is providing new knowledge for public health decision makers, based on the nine key areas for local authority public health action, described by the King's Fund. Many funded PHR projects are evaluating interventions, applied in a range of settings, across the identified key areas for local authority influence. For example, research has been funded on children and young people, and for some of the wider determinants of health, such as housing and travel. Other factors, such as spatial planning, or open and green spaces and leisure, are less represented in the PHR Programme. Further opportunities in research include interventions to improve the health of adolescents, adults in workplaces, and communities. Building evidence for public health interventions at local authority level is important to prioritise and implement effective changes to improve population health.
\end{abstract}

Keywords: Funding, Local government, Public Health, Research

\section{Background}

The National Institute for Health Research (NIHR) is the research and development arm of the National Health Service (NHS). It is funded by the English Department of Health with contributions from the Chief Scientist Office in Scotland, Health and Care Research Wales, and the Health and Social Care Research and Development Public Health Agency in Northern Ireland. The NIHR aims to improve the health and wealth of the nation through research by providing a health research system in which the NHS supports outstanding individuals working in world-class facilities, conducting leading-edge research focused on the needs of patients and the public [1].

All NIHR funding programmes may fund research relevant to public health; however, most programmes are primarily focussed on healthcare settings, services and

\footnotetext{
*Correspondence: h.dorling@soton.ac.uk

'NIHR Evaluation Trials and Studies Coordinating Centre (NETSCC), University of Southampton, Alpha House, Enterprise Road, Southampton SO16 7NS, UK Full list of author information is available at the end of the article
}

staff. Given the breadth of public health, a gap was identified in the funding of high quality, nationally important evaluations of interventions set outside of the NHS [2]. The NIHR Public Health Research (PHR) Programme was established to fill this gap in 2008. The remit of the PHR Programme is to fund evaluations on public health interventions, providing new knowledge on the benefits, costs, acceptability and wider impacts of non-NHS interventions intended to improve the health of the public and reduce inequalities in health [3]. The scope of the Programme is multi-disciplinary and broad, covering a wide range of public health interventions. The Programme is funded by the governments of all four United Kingdom countries.

The Programme aims to identify gaps in knowledge and fund research that provides high-quality evidence to fill such gaps [4]. PHR funds research through two routes - commissioned, where the Programme highlights an area that has the potential for developing new evidence, and researcher-led, where a research question is proposed by researchers. The Programme employs a 
needs-led approach to ensure that research is of the highest possible value to public health decision-makers, such as those working in local authorities. By this, we mean that the Programme prioritises funding research according to the needs of service providers and policymakers whose decisions can impact on the public's health. For example, the Programme Advisory Board, which is comprised of public health decision-makers, prioritises topics for future research and assesses submitted research applications for their potential importance in improving the evidence base for decision-making.

From its inception to June 2014, the PHR Programme had funded 83 projects. The portfolio of studies, including protocols and final reports, can be found at: www.nets.nihr.ac.uk/projects/phr. Although 5 years was a relatively short period for a funding programme, there were a sufficient number of studies to start reflecting on the balance of the portfolio and its future direction. This paper aims to describe the breadth of the portfolio, particularly in funded research which might inform local authorities. We use a framework for our description the nine areas for local authority action identified in a recent report by the King's Fund [5]. The nine key areas that can improve public health and reduce inequalities are 'The best start in life,' 'Healthy schools and pupils', 'Helping people find good jobs and stay in work', 'Active and safe travel', 'Warmer and safer homes', 'Access to green and open spaces and the role of leisure services', 'Strong communities, wellbeing and resilience', 'Public protection and regulatory services', and 'Health and spatial planning' (Table 1). The King's Fund is a leading independent health think tank in England, which is set up as a charity working to improve health and healthcare. Their vision is that the best possible healthcare is available to all [6], which involves providing advice or ideas to organisations to bring about change. There is no formal relationship between the King's Fund and the NIHR, but it is important for research funders, such as the NIHR, to be aware of the work the King's Fund is undertaking, as it may indicate the evidence user needs.

\section{Review}

The table below displays the spread of projects across the nine key areas, showing whether the project was funded through the commissioned or researcher-led work-stream.

Most projects are centred on the theme of 'Healthy schools and pupils', closely followed by 'The best start in life, 'Active and safe transport' and 'Public protection and regulatory services'. The other categories all have funded projects, but still provide an opportunity to fill important gaps in research. The 'Other' category represents projects which do not fall within the nine action areas. Local authorities are one of the main customers of the PHR Programme, but there are other customers, such as the third sector and health promotion services.

The commissioned work-stream represents $46 \%$ of the funded projects and the researcher-led work-stream represents $54 \%$ of the funded projects. Higher numbers of projects, from the commissioned work-stream, in particular areas may suggest topics with research interest or capacity. However, some research topics are particularly suited to the researcher-led work-stream, as opportunities arise. For example, changes to the built environment, shown in the 'Health and spatial planning' category, which are often evaluated as natural experiments. The commissioned work-stream encourages research for specific topics and populations to create a portfolio that fills important gaps in evidence.

\section{The best start in life}

There are nine research projects on early years interventions that feature in the PHR portfolio. The King's Fund recommends possible priority actions throughout their report [5]. For the best start in life, it is suggested that the most disadvantaged children and their families are

Table 1 Projects categorised by the nine areas for local authority action identified by the King's Fund

\begin{tabular}{llll}
\hline Project area & Total number of projects, $\mathrm{n}(\%)$ & Commissioned, $\mathrm{n}$ & Researcher-led, $\mathrm{n}$ \\
\hline The best start in life & $9(11)$ & 5 & 4 \\
Healthy schools and pupils & $22(27)$ & 11 & 11 \\
Helping people find jobs and stay in work & $2(2)$ & 2 & 0 \\
Active and safe transport & $7(8)$ & 3 & 4 \\
Warmer and safer homes & $5(6)$ & 1 & 3 \\
Access to green and open spaces and the role of leisure services & $5(6)$ & 4 & 3 \\
Strong communities, wellbeing and resilience & $4(5)$ & 7 & 0 \\
Public protection and regulatory services & $7(8)$ & 0 & 3 \\
Health and spatial planning & $3(4)$ & 9 & 3 \\
Other & $19(23)$ & 38 & 45 \\
\hline
\end{tabular}


targeted for support and interventions should be behaviour-focused, rather than just information-giving. Following the identification of an evidence gap and advertisement for proposals, PHR have funded a range of projects which involve parenting support programmes, with a particular focus on vulnerable children and families. This includes projects assessing the Family Nurse Partnership $[7,8]$ and improving outcomes for children who are exposed to domestic abuse or maltreatment $[9,10]$.

Enabling the best start in life is also addressed by support for positive health behaviours. 'Pre-schoolers in the Playground' is a pilot study of an intervention which aims to increase physical activity levels in children aged 18 months to 4 years old, funded through a commissioned call on outdoor community activity programmes. The intervention includes opening up school playgrounds for pre-school siblings to use as a safe place to take part in outdoor physical activity, whilst fitting in with the family's school run [11]. Another funded study to try to increase physical activity and improve nutrition in early years is the Nutrition and Physical Activity Self Assessment for Child Care. This programme trains staff who work in early years' settings to assess and improve the child care environment with respect to food, drink and physical activity [12].

\section{Healthy schools and pupils}

The King's Fund recommends promoting the school as a setting for healthy behaviours. Twenty-two PHR projects evaluate interventions delivered in schools. These include programmes to increase levels of physical activity, decrease sedentary behaviour, improve diet, prevent hazardous drinking, smoking and substance use, promote sexual health, build social and emotional wellbeing, and reduce bullying. Schools can be a valuable setting for public health interventions, as there are possibilities to intervene during lesson time or through extra-curricular activities, and to include families and communities. They have also been acknowledged as potentially effective settings for public health interventions, as they reach a large number of children and adolescents [13] and during the school year children spend a significant number of their waking hours at school [14]. This establishes an opportunity to promote health and wellbeing for all children, irrespective of their circumstances, developing knowledge and skills for the foundations for future health.

One of the areas the programme has concentrated on is reducing alcohol harm. The NICE Public Health Guidance for school-based interventions on alcohol noted a gap in evidence on the effectiveness of interventions for children and young people [15]. As this research question was viewed as an important gap to address by NICE, and in the remit of the PHR Programme, a commissioning brief was developed and advertised on interventions to prevent hazardous drinking of alcohol by school-aged children and young people. Three studies were awarded funding to address specific research questions in this area, using school-based interventions but involving families [16-18]. However, there are many other areas which can potentially influence positive behaviours for young people at school, such as changing the school environment to improve health behaviours. Although interventions in schools are well represented in the PHR portfolio, there are still many opportunities to extend the range of health topics. For example, further and higher education institutions may be a key educational setting to help young people improve their health; however, there is currently only one project in the PHR portfolio that uses a further education setting.

\section{Helping people find good jobs and stay in work}

The workplace provides an opportunity for improving health, as there is potential to reach large audiences, and having good working conditions is well known as a determinant of health [19]. Workplaces in the United Kingdom are moving towards a more active approach to reducing sickness absence. For instance, both the Black review of the health of the working age population [20] and the Black and Frost Independent Review of Sickness Absence [21], highlight the benefit of health and wellbeing programmes for businesses economically, and the importance of reducing sickness absence. The King's Fund recommends a number of actions to improve the health of employees such as promoting healthenhancing work cultures and implementing effective health promotion initiatives. The Programme has funded research projects in the workplace, including interventions aimed at encouraging walking to work [22] and reducing sickness absence [23]. There are many opportunities for further public health research in this area, such as promoting work cultures and environments to support the health of employees. A systematic review that recently explored workplace health promotion interventions for increasing physical activity showed some evidence that workplace physical activity interventions can be effective, although the overall results were inconclusive and there is a need for more robust studies [24]. Workplace health remains a priority area for research in the PHR Programme.

\section{Active and safe travel}

Transport can affect health positively by increasing physical activity levels and reducing isolation, or negatively, through transport injuries and air pollution. A range of studies have been funded by PHR on the public health impacts of infrastructure and provision, such as the effects of a new urban motorway [25], the health 
impacts of the Cambridgeshire Guided Busway [26] and 'On the buses' [27], which evaluated the impact of introducing free bus travel for young people with benefits for health and social inclusion. Other studies evaluate interventions which may affect safety, such as those aimed at maximising cycling safety [28], and assessing how reducing street lighting may affect crime and road traffic accidents at night [29]. The King's Fund report gives a number of recommendations, including changing public perception about cycling safety, cycle to work schemes, 20 mile per hour zones and changing the environment to improve walkability. These interventions could all be potentially researched to build a picture of the effectiveness and cost to local authorities. Research on transport remains a high priority for future health and sustainability, and further evidence will be important for local authorities to continue developing active and safe travel.

\section{Warmer and safer homes}

The King's Fund priority action areas include helping people keep their homes warmer and preventing accidents in the home. Several projects have been funded in this area, including the health impacts of structural energy performance investments in Wales [30], the impact of home energy efficiency interventions and winter fuel payments on winter- and cold-related mortality and morbidity in England [31], the health impact of meeting housing quality standards [32], and manipulating the appearance of steps and stairs to make them safer for older people to negotiate [33]. To build evidence relating to the King's Fund recommendations, further research is needed on how to prevent unintentional injuries in the home and how to provide healthy housing across the life-course, and for people with particular needs.

\section{Access to green and open spaces and the role of leisure services}

Access to green, open spaces and leisure services can shape people's physical and mental health, and build networks. One study from the PHR portfolio is evaluating whether changes to the natural environment can help psychological wellbeing [34]. Another project which uses green spaces includes understanding the impacts of care farms on health and wellbeing of offenders [35]. This aims to evaluate farming activities to help build selfesteem, improve physical and mental health, develop skills for employment and increase ability to interact socially.

The importance of creating more good quality open space, where it is lacking, has also been discussed in the Marmot Review as a means of tackling health inequalities [36]. However, the evidence in this area is not strong [37], and there are many opportunities for further research to help local authorities. Interventions designed to increase access to green and open spaces requires further evaluation; for instance, the King's Fund recommends working with local communities to help develop plans to help stimulate physical activity levels and engaging with community groups in the management of green spaces.

\section{Strong communities, wellbeing and resilience}

Community based interventions feature heavily in the PHR portfolio of funded projects. This approach aims to address some of the causes of inequalities, and can empower a large number of people. For instance, two research projects evaluate community engagement as an important way of developing public services that better meet people's needs and increase social cohesion [38, 39]. Other research evaluates interventions for specific communities [40], such as outreach programmes for health improvement of traveller communities. The research explores interventions that are adapted and taken to populations who do not, or cannot, access them as they are traditionally provided [39]. Potentially, there are possibilities for research, with other communities and with a different range of interventions. The King's Fund suggests building social capital and community-based assets to improve health, for example, by supporting volunteering interventions and working with wider public services. This may benefit from further research on the most effective ways of types of interventions and their implementation in communities.

\section{Public protection and regulatory services}

Protective and regulatory services can be key components to support health improvement. The King's Fund report [5] focuses on the regulation of takeaways and fast foods, the improvement of air quality and fire safety. Another area of public protection that the programme has funded is research that investigates the impact of a change in the density of alcohol outlets on alcohol consumption and alcohol-related harms to health in the community [41]. The findings from this study may potentially help local authorities consider changes to alcohol outlet density in the community to help improve health and reduce crime. Air pollution is a risk factor for a number of health problems, particularly for those with existing health conditions, or those who live in areas with poorer air quality. This is a complex area for assessing interventions. However, there is currently a project looking at the impacts of different pathways to meet the United Kingdom Climate Change Act commitment to $80 \%$ reduction on $\mathrm{CO}_{2}$ and other greenhouse gas emissions by 2050 [42]. Further research on the areas suggested by the King's Fund, and on other approaches for protective and regulatory services to improve population 
health and reduce health inequalities, could be helpful to local authorities.

\section{Health and spatial planning}

There is growing interest on the impact of the built environment on health [43]. This interest is reflected in the PHR portfolio, where the results can influence local authorities' decisions on spatial planning. All of the funded studies in this area have been defined by researchers, from the researcher-led work-stream. They cover a wide range of interventions, such as active design to increase physical activity levels [44] and the impact of urban regeneration on the social determinants of health, health behaviours and mental health [45].

A PHR funded research project, which has recently been published, conducted a systematic review to synthesize qualitative evidence from the United Kingdom on fear of crime and the environment [46]. The review suggested that any attempt to address fear of crime through the physical environment in isolation is unlikely to succeed, and consideration would need to be given to the social environment, or the socioeconomic or policy context, to establish positive changes. The findings of this study may be useful to help inform decision makers. However, there are still many opportunities to evaluate interventions in this broad area such as indoor air quality, building conditions and infrastructure design for health.

\section{Reflection on the portfolio of research}

This analysis provides a snapshot of the portfolio of funded research. The King's Fund nine key action areas were chosen as a framework as it is recent and relevant to the main customers of the PHR Programme. The King's Fund has noted the strengths of interventions in each area that allows reflection on which interventions will deliver the best results [5]. Over a quarter of the projects fall within the 'Healthy Schools and Pupils' category, although there still remain gaps within this category. For example, the consideration of different settings within education such as further and higher education. Other categories which follow closely behind include 'The best start in life,' 'Active and safe transport' and 'Public protection and regulatory services'. The King's Fund report highlights that these interventions may have a significant impact to improve health and reduce inequalities, but they require more investment and it may take a long time to demonstrate impact.

The categories with the least amount of projects include 'Helping people find jobs' and 'Health and spatial planning'. However, the report highlights that all categories are strong candidates for action to improve population health and shows how health determinants may affect one another. As a result, these may need further analysis to consider the most important gaps to fill within these areas for local authorities, using the needs-led prioritisation process. Possible topics for research are reviewed by advisory groups of external experts and public members to assess the need for the research.

It is important to consider the impact of the research. However, as much of the research has not yet been completed or has only recently been published, this will be assessed at a later time. Interest in the research findings can be assessed now by process and surrogate measures, such as recording the number of report downloads, citations, collecting case studies and using online platforms, such as Researchfish (www.researchfish.com), which enables research funders to track the impacts of their investments. An external review may be commissioned, such as the Raftery, Hanney and Buxton paper, which assesses the impact of the NHS Health Technology Assessment Programme in England [47].

\section{Conclusions}

Building evidence for public health interventions at local authority level is important to prioritise and implement effective changes to improve population health. This paper provides an opportunity to reflect on the diversity of public health interventions outside of the NHS in the PHR Programme, based on the nine key areas for local authority public health action, as described by the King's Fund. The programme has an expanding portfolio of relevant and potentially useful research for local authorities. The 'Best start in life, 'Healthy schools and pupils', 'Active and safe travel', and 'Warmer and safer homes' appear to be better represented than other key areas. When reflecting on the potential impact that the interventions could have, all are in categories which the King's Fund report suggests are likely to be highly important for their impact on population health. There are many opportunities for researchers to fill gaps in evidence for local authorities by providing new knowledge and give further breadth to the PHR portfolio.

The authors of this review invite researchers to submit proposals relating to the evidence gaps identified within the remit of the PHR Programme, or other NIHR programmes, by submitting an application to the researcher-led work-stream. The Programme would also like to encourage submission of suggestions for potential future research www.nets.nihr.ac.uk/identifying-research/ make-a-suggestion.

\section{Abbreviations}

PHR: Public Health Research; NHS: National Health Service; NIHR: National Institute for Health Research.

\section{Competing interests}

$\mathrm{HD}, \mathrm{LO}$ and MW work at the National Institute for Health Research (NIHR), Evaluation, Trials and Studies Coordinating Centre (NETSCC), the secretariat 
which manages the NETS Programmes, including the NIHR Public Health Research (PHR) Programme. AC is employed by the University of Southampton, and has worked in various parts of NETSCC since 2005. AC is also an associate director at the Southampton Clinical Trials Unit, which receives CTU support funding from NIHR and applies to NIHR programmes for fund to conduct clinical trials. NETSCC is funded by the NIHR.

\section{Authors' contributions}

HD led the research and the writing of the paper. All authors contributed to or commented on successive drafts of the paper. All authors contributed to the steering of the review. All authors read and approved the final manuscript.

\section{Acknowledgements}

We would like to thank Professor Catherine Law, who was the Programme Director of the NIHR PHR Programme until 2014. We would also like to thank those who have contributed to the success of the NIHR PHR Programme, including members of both the Programme Advisory Board and Research Funding Board, applicants to the programme, and other members of the PHR team at NETSCC. The views and opinions expressed are those of the authors and do not necessarily reflect those of the Department of Health and of NETSCC.

\section{Author details}

'NIHR Evaluation Trials and Studies Coordinating Centre (NETSCC), University of Southampton, Alpha House, Enterprise Road, Southampton SO16 7NS, UK. ${ }^{2}$ Wessex Institute, University of Southampton, Southampton, UK. ${ }^{3}$ University Hospital Southampton NHS Foundation Trust, Southampton, UK.

Received: 18 March 2015 Accepted: 30 November 2015 Published online: 11 December 2015

\section{References}

1. The National Institute for Health Research. The National Institute for Health Research. 2015. www.nihr.ac.uk/about/mission-of-the-nihr.htm. Accessed 12 November 2015.

2. Milne R, Law C. The NIHR public health research programme: developing evidence for public health decision-makers. J Public Health. 2009;31(4):589-92. doi:10.1093/pubmed/fdp095.

3. NIHR Public Health Research Programme. Public Health Research (PHR) Programme. 2013. www.nets.nihr.ac.uk/programmes/phr. Accessed 25 November 2013

4. National Institute for Health Research. Needs-led, science-added. 2014 www.nets.nihr.ac.uk/about/needs-led-science-added. Accessed 6 March 2014

5. Buck D, Gregory S. Improving the public's health. A resource for local authorities. London: The King's Fund; 2013.

6. The King's Fund. About Us. 2015. www.kingsfund.org.uk/about-us. Accessed 12 November 2015.

7. Robling M. PHR - 11/3002/11: Evaluating the long-term effectiveness, and the cost and consequences of the Family Nurse Partnership parenting support programme in reducing maltreatment in young children. www.nets.nihr.ac.uk/projects/phr/11300211. Accessed 3 February 2014.

8. Barnes J. PHR - 11/3002/02: Randomised trial of the effectiveness of Group Family Nurse Partnership (gFNP) programme in improving outcomes for high-risk mothers and preventing abuse. www.nets.nihr.ac.uk/projects/phr/ 11300202. Accessed 3 February 2014.

9. Feder G. PHR - 11/3007/01: An overview of interventions aimed at IMPRoving Outcomes for children exposed to domestic ViolencE: systematic review, evidence synthesis and research recommendations. (IMPROVE). www.nets.nihr.ac.uk/projects/phr/11300701. Accessed 3 February 2014

10. Henderson M. PHR - 11/3002/01: Trial of Healthy Relationship Initiatives for the Very Early-years (THRIVE): a Three-Arm Randomised Controlled Trial for Mothers Identified as Vulnerable in Pregnancy and their Babies who are at High Risk of Maltreatment. www.nets.nihr.ac.uk/projects/phr/11300201. Accessed 3 February 2014.

11. Wright J. PHR - 11/3001/16: "Pre-schoolers in the Playground (PiP)" - a pilot cluster randomised controlled trial of a physical activity intervention for children aged 18 months - 4 years old. www.nets.nihr.ac.uk/projects/phr/ 11300116. Accessed 3 February 2014.
12. Kipping R. PHR - 12/153/39: NAP SACC UK: A feasibility cluster randomised controlled trial in child care settings to increase physical activity and healthy eating in 2-4 year olds. www.nets.nihr.ac.uk/projects/phr/1215339. Accessed 3 February 2014.

13. Lobstein T, Swinburn B. Health promotion to prevent obesity. In: Global perspectives on health promotion effectiveness. New York: Springer; 2007. p. $125-50$

14. Fox KR, Cooper A, McKenna J. The school and promotion of children's health-enhancing physical activity: perspectives from the United Kingdom. J Teach Phys Educ. 2004;23(4):338-58.

15. National Institute for Health and Care Excellence. School-based interventions on alcohol (PH7). 2007. guidance.nice.org.uk/PH7. Accessed 25 November 2013.

16. Segrott J. PHR - 10/3002/03: Preventing alcohol misuse in young people: An exploratory trial of the Kids, Adults Together (KAT) Programme. www.nets. nihr.ac.uk/projects/phr/10300203. Accessed 3 February 2014.

17. Sumnall H. PHR - 10/3002/09: Steps towards alcohol misuse prevention programme (STAMPP): a school and community based cluster randomised controlled trial. www.nets.nihr.ac.uk/projects/phr/10300209. Accessed 3 February 2014.

18. Newbury-Birch D. PHR - 10/3002/07: A feasibility trial of screening and brief alcohol intervention to prevent hazardous drinking in young people aged 14-15 in a high school setting (SIPS JR-HIGH). www.nets.nihr.ac.uk/projects/ phr/10300207. Accessed 3 February 2014.

19. Quintiliani L, Sattelmair J, Sorensen G. The workplace as a setting for interventions to improve diet and promote physical activity. In: Documento técnico preparado para el evento conjunto OMS/Foro Económico Mundial sobre la prevención de las enfermedades no transmisibles en el lugar de trabajo. Geneva: WHO; 2007.

20. Black DC. Working for a healthier tomorrow. London: The Stationary Office; 2008

21. Black DC, Frost D. Health at work - an independent review of sickness absence. London: The Stationary Office; 2011.

22. Tully M. PHR - 12/133/04: A feasibility study and pilot RCT of a peer-led walking programme to increase physical activity in inactive older adults: Walk With Me Study. www.nets.nihr.ac.uk/projects/phr/1213304. Accessed 4 February 2014.

23. Stansfeld S. PHR - 10/3007/06: Pilot Study of a randomised trial of a guided e-learning health promotion intervention based on management standards for the improvement of employee wellbeing and reduction of sickness absence. www.nets.nihr.ac.uk/projects/phr/10300706. Accessed 4 February 2014.

24. Malik SH, Blake H, Suggs LS. A systematic review of workplace health promotion interventions for increasing physical activity. Br J Health Psychol. 2014;19(1):149-80. doi:10.1111/bjhp.12052.

25. Ogilvie D. PHR - 11/3005/07: The M74 study: longitudinal follow-up of the health effects of a new urban motorway. www.nets.nihr.ac.uk/projects/phr/ 11300507. Accessed 4 February 2014.

26. Ogilvie D. PHR - 09/3001/06: Health impacts of the Cambridgeshire Guided Busway. www.nets.nihr.ac.uk/projects/phr/09300106. Accessed 4 February 2014.

27. Green J. PHR - 09/3001/13: On the buses: a mixed-method evaluation of the impact of free bus travel for young people on the public health. www.nets. nihr.ac.uk/projects/phr/09300113. Accessed 4 February 2014.

28. Mulvaney C. PHR - 11/3020/04: Maximising cycling safety to improve public health: a Cochrane review to assess the effectiveness of cycling infrastructure at reducing the risk of cycling injuries in cyclists. www.nets. nihr.ac.uk/projects/phr/11302004. Accessed 4 February 2014.

29. Edwards P. PHR - 11/3004/02: What is the effect of reduced street lighting on crime and road traffic accidents at night? A mixed methods study. www nets.nihr.ac.uk/projects/phr/11300402. Accessed 4 February 2014.

30. Poortinga W. PHR - 11/3020/05: The health impacts of structural energy performance investments in Wales: an evaluation of the Arbed Programme. www.nets.nihr.ac.uk/projects/phr/11302005. Accessed 4 February 2014.

31. Wilkinson P. PHR - 11/3005/31: The impact of home energy efficiency interventions and winter fuel payments on winter- and cold-related mortality and morbidity in England: evaluation of a natural experiment. www.nets.nihr.ac.uk/projects/phr/11300531. Accessed 4 February 2014. 
32. Lyons R. PHR - 09/3006/02: Health impact, and economic value, of meeting housing quality standards. www.nets.nihr.ac.uk/projects/phr/09300602. Accessed 4 March 2014.

33. Elliott D. PHR - 10/3009/06: Manipulating the appearance of stairs to improve safety. www.nets.nihr.ac.uk/projects/phr/10300906. Accessed 4 February 2014.

34. Ward Thompson C. PHR - 10/3005/18: How effective is the Forestry Commission Scotland $s$ woodland improvement programme - Woods In and Around Towns (WIAT) - at improving psychological wellbeing in deprived communities? www.nets.nihr.ac.uk/projects/phr/10300518. Accessed 5 February 2014.

35. Elsey H. PHR - 11/3050/08: Understanding the Impacts of Care Farms on Health and Well-being: A Pilot study to inform the design of a follow-on study to assess the cost-effectiveness of care farms in improving health and wellbeing and reducing re-offending. www.nets.nihr.ac.uk/projects/phr/ 11305008. Accessed 5 February 2014.

36. Marmot M. Fair Society Healthy Lives (The Marmot Review). London: UCL Institute of Health Equity; 2010.

37. Lee ACK, Maheswaran R. The health benefits of urban green spaces: a review of the evidence. J Public Health. 2011;33(2):212-22. doi:10.1093/ pubmed/fdq068.

38. Popay J. PHR - 09/3008/07: The impact on health inequalities of approaches to community engagement in the New Deal for Communities regeneration initiative: a mixed-methods evaluation www.nets.nihr.ac.uk/projects/phr/ 09300807. Accessed 5 February 2014.

39. Thomas J. PHR - 09/3008/11: Community engagement to reduce inequalities in health: a systematic review, meta-analysis and economic analysis. www.nets.nihr.ac.uk/projects/phr/09300811. 5 February 2014.

40. Carr S. PHR - 10/3004/02: Outreach programmes for health improvement of Traveller Communities: a synthesis of evidence. www.nets.nihr.ac.uk/ projects/phr/10300402. Accessed 5 February 2014.

41. Fone D. PHR - 09/3007/02: Change in alcohol outlet density and alcoholrelated harm to population health. www.nets.nihr.ac.uk/projects/phr/ 09300702. Accessed 4 March 2014.

42. Williams M. PHR - 11/3005/13: Public health air pollution impacts of different pathways to meet the UK Climate Change Act commitment to $80 \%$ reduction on $\mathrm{CO}_{2}$ and other greenhouse gas emissions by 2050 . www.nets.nihr.ac.uk/projects/phr/11300513. Accessed 4 February 2014.

43. Villanueva K, Pereira G, Knuiman M, Bull F, Wood L, Christian H, et al. The impact of the built environment on health across the life course: design of a cross-sectional data linkage study. BMJ Open. 2013;3(1):e002482. doi:10.1136/bmjopen-2012-002482.

44. Owen C. PHR - 12/211/69: Does active design increase walking and cycling? Evaluation of a natural experiment examining whether moving into housing in East Village increases family levels of physical activity, particularly walking and cycling. www.nets.nihr.ac.uk/projects/phr/1221169. Accessed 3 February 2014

45. Cummins S. PHR - 09/3005/09: Olympic Regeneration in East London (ORiEL) Study. www.nets.nihr.ac.uk/projects/phr/09300509. Accessed 4 February 2014.

46. Petticrew M. PHR - 09/3000/14: Crime, fear of crime (CFOC) and mental health: evidence synthesis of theory and effectiveness of interventions. www.nets.nihr.ac.uk/projects/phr/09300014. Accessed 4 February 2014

47. Raftery J, Hanney S, Green C, Buxton M. Assessing the impact of England's National Health Service R\&D Health Technology Assessment program using the "payback" approach. Int J Technol Assess Health Care. 2009;25(1):1-5.

\section{Submit your next manuscript to BioMed Central and we will help you at every step:}

- We accept pre-submission inquiries

- Our selector tool helps you to find the most relevant journal

- We provide round the clock customer support

- Convenient online submission

- Thorough peer review

- Inclusion in PubMed and all major indexing services

- Maximum visibility for your research

Submit your manuscript at www.biomedcentral.com/submit

) Biomed Central 